\title{
NANOFIBRILLATED CELLULOSE REINFORCED POLYPROPYLENE COMPOSITES: INFLUENCE OF SILANE (SI-69) SURFACE MODIFICATION
}

\author{
K. D. H. N. KAHAVITA, ${ }^{*}$ A. M. P. B. SAMARASEKARA, ${ }^{*}$ D. A. S. AMARASINGHE ${ }^{*}$ and \\ L. KARUNANAYAKE** \\ "Department of Materials Science and Engineering, University of Moratuwa, Katubedda, \\ Moratuwa 10400, Sri Lanka \\ *** Department of Polymer Science, University of Sri Jayewardenepura, \\ Nugegoda 10250, Sri Lanka \\ \Corresponding author: A. M. P. B. Samarasekara, banduamp@gmail.com
}

Received April 19, 2020

\begin{abstract}
Nanocellulose serves as next-generation renewable reinforcement to produce high performance nanocomposites. The present study discusses the effect of silane (Si-69) surface modification on thermal and mechanical properties of nanofibrillated cellulose (CNF) reinforced polypropylene composites. Mechanical, thermal, water absorption and melt flow index of untreated and silane treated $\mathrm{CNF}$ with up to $5 \mathrm{wt} \%$ reinforced composites were studied against pure polypropylene (PP). The thermal and mechanical properties, such as tensile strength, impact strength and hardness, of silane treated CNF reinforced composites showed a significant improvement, in comparison with the untreated $\mathrm{CNF}$ based composites and reference pure PP. However, the addition of both treated and untreated CNF slightly increased water absorption and reduced the processability. The experimental results clearly show the effectiveness of the reinforcement behavior of silane (Si-69) modified CNF in the PP matrix, compared to untreated CNF. The best mechanical and thermal properties were obtained from $3.5 \mathrm{wt} \%$ silane surface modified CNF reinforced composite.
\end{abstract}

Keywords: polypropylene, nano-fibrillated cellulose, silane (si-69), surface modification, composite

\section{INTRODUCTION}

Nanoparticle reinforced composite materials are spread worldwide for different applications, as these reinforcements improve the properties of neat materials or conventional composites. Unlike the particles in the micrometer dimensions, nanoparticles have a very high surface to volume ratio. Therefore, large amounts of atoms occupy the surface and surface properties become more prominent. ${ }^{1}$ Recently, nanoparticles extracted from natural sources have become widely used as reinforcing agent for composites to replace synthetic materials, due to their abundance, renewability, biodegradability and cost efficiency. Numerous types of natural polymers, which can be extracted as nanoparticles, such as lignocellulose, starch and proteins, are found on the earth. However, cellulose has gained more attention due to its higher availability. Cellulose is mainly extracted from natural plants or plant waste materials, such as crop and timber residues. Also, cellulose is present within some bacterial sources, green algae species and fungi species.
Recent researchers have discovered the possibility to separate cellulose from tunicates (a marine invertebrate animal), which is the only species that produces cellulose in the animal kingdom. However, the amount of cellulose present in these species is insignificant, when compared to plant materials. ${ }^{2-9}$

The cellulose extracted from plant materials can be converted to either nanocrystalline cellulose (CNC) or nanofibrillated cellulose (CNF), using different biological, chemical, or mechanical approaches. ${ }^{6,10}$ Both CNC and CNF are polysaccharides, and the monomer here is glucose. However, $\mathrm{CNC}$ is a short-chain polysaccharide with high crystallinity, while CNF consists of both amorphous and crystalline areas, with long chains of glucose units interconnected by $\beta-1,4$-glycosidic bonds. Therefore, CNF can produce a fibrous, thin three-dimensional network and can be used to reinforce composite materials to improve their mechanical properties. ${ }^{11}$ 
There are mainly four types of composite materials: polymer, metal, ceramic, and carbon composites, depending on the matrix material used. $^{12} \mathrm{CNF}$ is commonly used to reinforce polymer matrices, and they are further categorized as natural and synthetic composites, depending on the nature of the matrix. ${ }^{13}$ Due to its unique properties, $\mathrm{CNF}$ is frequently used as a reinforcement of both biocomposites, for instance, polylactic acid, ${ }^{14,15}$ starch, ${ }^{16,17}$ and plastic composites, such as polyolefin ${ }^{18,19}$ and polystyrene. ${ }^{20}$ This research is focused on the production of a synthetic thermoplastic polypropylene-based composite to enhance the properties of the pure polymer.

Polypropylene (PP) is a semicrystalline, simple polyolefin with moderate thermal and mechanical properties, with high chemical and water resistance. ${ }^{21}$ Therefore, PP has gained massive attention in the thermoplastic industry and scientific research field. It is a potential base material for numerous applications. Based on the spatial arrangement of the pendant groups, PP is classified into three classes: as atactic (aPP), syndiotactic ( $\mathrm{sPP}$ ) and isotactic polypropylene (iPP). When compared to the SPP and iPP, aPP has low mechanical properties because of the random orientation of pendant groups, which leads to the formation of an amorphous material. ${ }^{22}$ Meanwhile, iPP is the most commonly used PP type due to its excellent properties and better processability, compared to $\mathrm{SPP} .^{23}$

In nature, nanofibrillated cellulose has hydrophilic characteristics due to the presence of hydroxyl groups. Polypropylene is hydrophobic due to the presence of nonpolar methyl groups on the surface. Therefore, these two materials are not compatible with each other. The standard way to overcome this obstacle is to modify the surface. The conversion of the hydrophilic CNF surface to hydrophobic can be done using several chemical and physical surface treatment methods. However, chemical surface modification techniques offer more stable results than physical methods due to the formation of strong intermolecular bonds, including covalent bonds. ${ }^{24}$ Chemical surface modifications are further subdivided into two classes: i) coupling agents ${ }^{25}$ and ii) polymer drafting. $^{26}$ Nanocellulose modified by coupling agents effectively transfers forces from the matrix to the reinforcement. Therefore, coupling agents act as better load transferring agents and, in return, improve the mechanical properties of the composites. ${ }^{24}$ There are different types of coupling agents available on the market; however, for this research, silane ( $\mathrm{Si}$ 69) has been chosen due to its low cost, availability and simplicity of the process.

There are three major components in the process. They are the matrix material, the reinforcement and the surface modifier. The ratios of each component used have a substantial effect on the properties of the ultimate product. In general, reinforcement amounts differ depending on factors, such as the type of the matrix, the fabrication method and the aspect ratio. Therefore, it is of great importance to find the most effective reinforcement composition that improves the properties of the composite, compared to the neat matrix material. According to previous studies, the reinforcement reaches an optimum level at CNF loading of 1-5 wt $\% .^{18,19,27}$

There are two types of fabrication methods commonly used for the fabrication of natural fiber-reinforced composites. When chemicals are used on a small scale, the solvent processing method could be used to produce nanocomposites. However, the properties of the composite could be reduced because of the partial removal of the solvent. Therefore, melt processing is a better technique to obtain homogeneous samples, with uniform properties. ${ }^{28}$ The other critical parameters are the process conditions, such as temperature, pressure, time, rotation speed of the internal mixer, fill factor, etc. The mixing temperature is kept at $\leq 200{ }^{\circ} \mathrm{C}$ to avoid the degradation of natural fibers and thermoplastic matrix materials. ${ }^{29}$ The fill factor of the mixing machine should be higher than 0.8 to achieve uniform distribution. Furthermore, both time and rotation speed have an influence on the dispersion of the reinforcement agent in the matrix, and it was reported that the use of moderate levels is the best. $^{30}$

\section{EXPERIMENTAL}

\section{Materials}

Spray-dried nanofibrillated cellulose (CAS Number: 9004-34-6) was purchased from Process Development Center, University of Maine. It was a white color, odorless, $98 \%$ (w/w) dry powder with 1.5 $\mathrm{g} / \mathrm{cm}^{3}$ density. Fibers were of $50 \pm 15 \mathrm{~nm}$ width, and they are naturally hydrophilic. Polypropylene homopolymer (TASNEE PP H4260M) was used as a matrix material with a melt flow index (MFI) of 23 $\mathrm{g} / 10 \mathrm{~min}, 165{ }^{\circ} \mathrm{C}$ melting temperature, and $0.9 \mathrm{~g} / \mathrm{cm}^{3}$ density. The surface modifier (30 wt\%), Si-69 (Bis[3(triethoxysilyl)propyl]polysulfide), and all the other 
analytical grade chemicals were obtained from Sigma Aldrich.

\section{Surface modification of CNF}

An appropriate amount of CNF and ethanol (85\%) in a 1:10 ratio (wt\%) were weighed and placed into a beaker, and the mixture was named $\mathrm{MX}_{1}$. Then, ultrasonic waves (frequency less than $20 \mathrm{kHz}$ ) were applied to $\mathrm{MX}_{1}$ for $40 \mathrm{~min}$. At the same time, a separate beaker was taken and relevant volumes of Si69 and ethanol were added $\left(\mathrm{MX}_{2}\right)$, and $\mathrm{MX}_{2}$ was kept $10 \mathrm{~min}$ for the hydrolysis process. After that, the two mixtures of $\mathrm{MX}_{1}$ and $\mathrm{MX}_{2}$ were mixed together, and the sonication process was repeated for another 40 min. Later, a concentrated mixture was observed with the application of moderate heat, while stirring. Finally, solidified, silylated CNF was recovered after the drying process.

\section{Composite fabrication}

Two separate series of unmodified CNF reinforced composite (U-CNF-PP) and silane (Si-69) surface modified CNF reinforced composite (Si-CNF-PP) samples from 0 to $5 \%(\mathrm{w} / \mathrm{w})(0.5 \%$ increment per sample) were prepared for better observation of surface modification and property improvement. Sheets of all the composites and pure PP samples were made by the melt processing technique (CT Internal Mixer MX300) and the processing parameters, such as time, temperature and rotor speed, were controlled at $8 \mathrm{~min}$, $180^{\circ} \mathrm{C}$ and $65 \mathrm{rpm}$, respectively.

The thickness of the nanocomposite is a critical parameter for many properties. In the past, researchers have used thicknesses between 0.1-2.5 mm, as it (thickness) depends on the application of the produced composite. $^{31-33}$ Sheets were prepared according to ASTM D3039 standards and the thickness was maintained at $2.5 \mathrm{~mm}$ for random fiber orientations. The prepared sheets were then molded under $180{ }^{\circ} \mathrm{C}$ temperature and 0.5 psi pressure using a compression molding press to obtain composite samples.

\section{Characterization}

The reference pure PP (Ref-PP) sample and the fabricated U-CNF-PP and Si-CNF-PP composite samples were analyzed in terms of mechanical properties, such as tensile strength, impact strength and hardness. Thermal properties were investigated using Differential Thermal Analysis (DTA) and ThermoGravimetric-Analysis (TGA). Water absorption and melt flow index (MFI) tests were also carried out.

\section{Tensile strength}

This test was conducted according to the standard test method for the tensile test for plastics (ASTM D 638) and five replicates of each sample were used to calculate the average value. The stress-strain curves were obtained using an HTE Hounsfield universal tester, at room temperature.

\section{Impact strength}

Five samples of each composite were prepared according to the standard method for the Izod impact strength of plastics (ISO 180:2000). The length, width and thickness of the samples were $80 \mathrm{~mm}, 10 \mathrm{~mm}$ and $2 \mathrm{~mm}$, respectively. A notch of $2 \mathrm{~mm}$ depth was milled into each sample. The remaining width at the notch was estimated to be $8 \mathrm{~mm}$. The impact angle was measured using the Izod impact testing machine (HUNG TA HT-8041B), and the value was converted to energy lost per unit cross-sectional area at the notch $\left(\mathrm{kJ} / \mathrm{m}^{2}\right)$.

\section{Hardness}

Five readings of each sample were used to obtain hardness values according to the standard test method of the hardness of plastics (ASTM D2240 standards) using the Shore Durometer D scale.

\section{Differential thermal analysis (DTA)}

The test was conducted for $5 \mathrm{mg}$ of sample at the temperature between $25-600{ }^{\circ} \mathrm{C}$ at a heating rate of 10 ${ }^{\circ} \mathrm{C} / \mathrm{min}$, using TA Instruments-SDT Q600 machine.

\section{Water absorption}

Five test pieces from each sample were cut according to the ASTM D 570 standard test method. The initial weight of each test piece was recorded, then the test pieces were soaked in distilled water at room temperature for 24 hours. After 24 hours, the test pieces were reweighed to calculate the water absorption percentage.

\section{Melt flow index (MFI)}

ASTM D1238, the standard test method for the flow rate of thermoplastics, using an extrusion plastometer, was followed, using the CSI melt flow indexer (model: Mfi2-115). Initially, the samples were cut into small, equally sized pieces and were fed to the indexer. The temperature and the load were used as $230{ }^{\circ} \mathrm{C}$, and $2.16 \mathrm{~kg}$, respectively, as stated in the condition "L" of the ASTM testing method, and five replicates of each sample were tested to calculate the average MFI value.

\section{RESULTS AND DISCUSSION Surface modification of CNF Tensile strength}

The tensile strength of Ref-PP and different compositions of U-CNF-PP (unmodified CNF reinforced composite) and $\mathrm{Si}-\mathrm{CNF}-\mathrm{PP}$ (silane modified CNF reinforced composite) composites are shown in Figure 1. All the Si-CNF-PP samples show higher tensile strength values than the Ref-PP sample (24.7 MPa). However, the UCNF-PP composite series show a moderate reduction with the increase in $\mathrm{CNF}$ percentage 


\section{KAHAVITAGE DONA HIMANTHI NIMREKHA KAHAVITA et al.}

(Fig. 1). The improvement in the tensile strength of all the samples in the Si-CNF-PP composite series provides evidence for better interaction between the reinforcement and the matrix (Fig. 1). Naturally, CNF is hydrophilic owing to the large $\mathrm{OH}$ group density present on the surface. However, the PP matrix is hydrophobic due to the hydrocarbon groups on the surface. This incompatibility leads to weak property enhancement in the composite. During the proposed surface modification process, silane molecules were chemically bonded to the CNF surface, reducing the hydrophilicity of the CNF surface by replacing the surface hydroxyl groups. ${ }^{34,35}$ Due to the increased hydrophobicity of the CNF surface, stronger interfacial adhesion occurred between the two phases. ${ }^{38}$ Therefore, better mechanical properties were expected from the Si-CNF-PP composites, compared to ref-PP. However, compared to the Si-CNF-PP composites, a reduction of the tensile strength was observed for all the U-CNF-PP samples, emphasizing the weak interfacial bonding between the filler and the matrix. The dispersion of two incompatible phases tends to produce phase separation through agglomeration, to reach

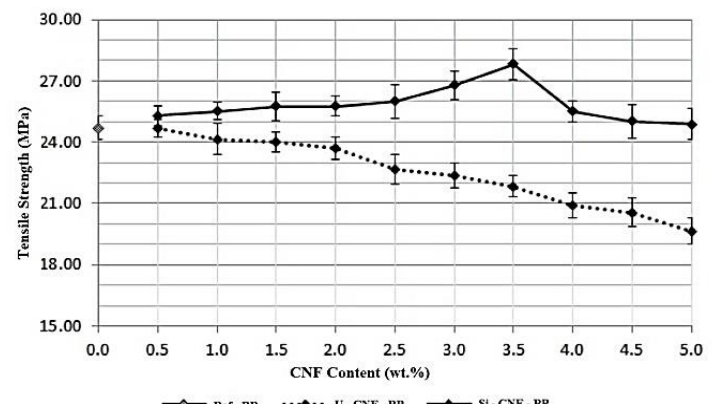

Figure 1: Comparison between the tensile strength of U-CNF-PP and Si-CNF-PP samples with respect to Ref-PP

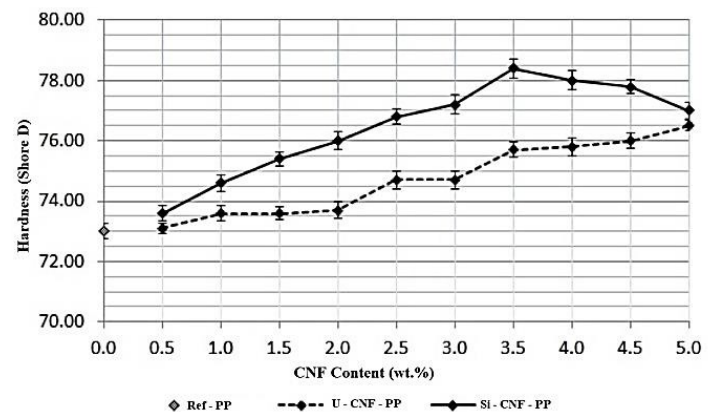

Figure 3: Comparison between the hardness of UCNF-PP and Si-CNF-PP samples with respect to Ref$\mathrm{PP}$ reduced Gibbs energy states. The formation of large $\mathrm{CNF}$ agglomerates could also contribute to lower mechanical properties. These agglomerates may act as stress raisers and initiate micro-cracks.

\section{Impact strength}

Impact strength is a measure of a material's ability to withstand a maximum sudden load. The impact strength of PP without reinforcement shows a value of $2.16 \mathrm{~kJ} \mathrm{~m}^{-2}$ (this is the impact strength of Ref-PP). Compared to the impact strength of Ref-PP $\left(2.16 \mathrm{~kJ} \mathrm{~m}^{-2}\right)$, significant improvements were observed in both the Si-CNFPP series and the U-CNF-PP series (Fig. 2). This increase is due to the reinforcing effect of CNF fibers. The impact strength of U-CNF-PP composites does not show a high dependency on the CNF content. However, the impact strength of the Si-CNF-PP composite series shows relatively higher dependence on the CNF content. The impact strength of the Si-CNF-PP composite series was always higher than that of the corresponding U-CNF-PP series samples. It is an indication that better compatibility has been achieved through silane surface modifications.

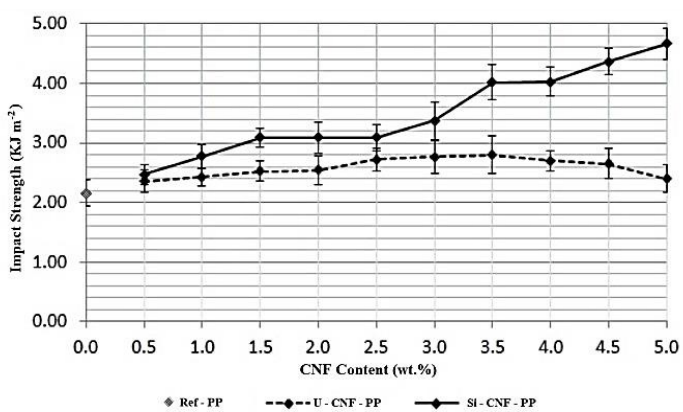

Figure 2: Comparison between the impact strength of U-CNF-PP and Si-CNF-PP samples with respect to Ref-PP

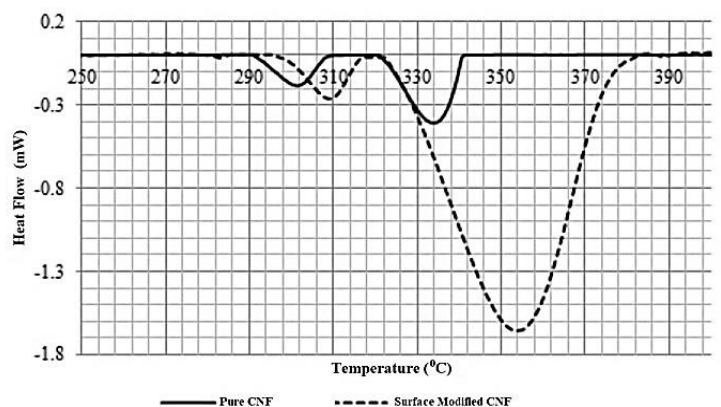

Figure 4: Comparison between the baseline corrected DTA curves of pure and silane (si-69) surface modified CNF 


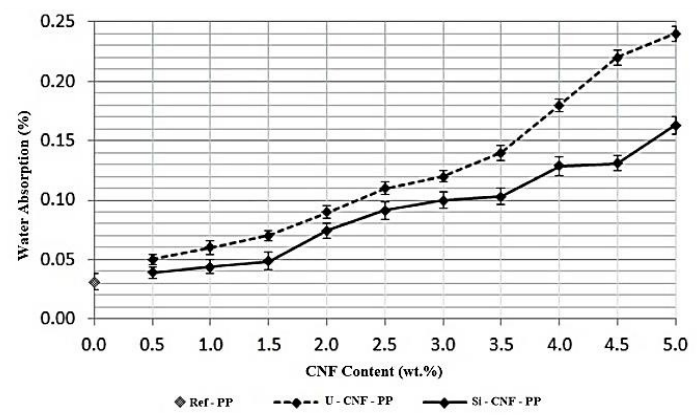

Figure 5: Comparison between the water absorption percentage of U-CNF-PP and Si-CNF-PP samples with respect to Ref-PP

\section{Hardness}

The incorporation of CNF, in both surface modified or unmodified forms, into the matrix improved the hardness of the composite. However, the U-CNF-PP composite series exhibited relatively lower improvement, because of the incompatible nature of CNF with PP. With respect to the U-CNF-PP composites, the $\mathrm{Si}$ CNF-PP series has a rapid increase in the hardness values with the silane treated CNF percentage. The silane surface modification improves the wettability of PP on CNF, contributing to better bonding between $\mathrm{CNF}$ and PP interfaces. ${ }^{38}$

\section{Thermal analysis}

Baseline-corrected DSC thermograms of surface-modified and unmodified CNF are shown in Figure 4. As illustrated in the thermogram, the two prominent endothermic peaks have shifted towards higher temperatures. At the lower temperature region, there is an endothermic peak around $100{ }^{\circ} \mathrm{C}$. This peak is directly correlated to water and other volatile evaporation. It was not shown in the figure as it is not relevant for this discussion. Cellulose pyrolysis starts with the depolymerization of cellulose to form active cellulose. This step is not associated with any rapid mass losses. Therefore, it is hidden in the DTG (or TGA) thermograms. In the pure cellulose DSC thermograms, there are two distinct peaks around $300{ }^{\circ} \mathrm{C}$ and $330{ }^{\circ} \mathrm{C}$. These peaks generally correspond to condensable vapor or tar formation during the cellulose pyrolysis. ${ }^{39,40}$ The area below the DTA curve represents the enthalpy or the energy requirement to the reaction. ${ }^{41}$ Therefore, the surface modified CNF leads to an enhancement in heat stability, compared to pure CNF, because the energy required to break the long chain macromolecular structure of nanocellulose is higher, due to the formation of a silylated cover around CNF.

\section{Water absorption percentage}

The water absorption percentages of the SiCNF-PP and U-CNF-PP composites are shown in Figure 5. The lowest water absorption is shown by the Ref-PP sample, because of the nonpolar nature of the polypropylene. Nevertheless, the water absorption of the Si-CNF-PP composite series is lower than that of the U-CNF-PP series, because of the formation of a nonpolar silylated cover around the fibers, which improves the thermal stability. However, surface modification cannot be achieved completely in practice. Therefore, the Si-CNF-PP composites present water absorption values in between those of RefPP and the U-CNF-PP composites with relevant loadings of CNF. The analysis of water absorption is very important for dimensional stability, as well as biodegradability. If the water absorption level is high, it means the dimensional stability is becoming low and the biodegradability of the material is getting high, because the presence of water creates low interfacial adhesion between the fiber and the matrix, and then the fibers become the food source of microbes in the soil, thus improving the biodegradability. ${ }^{42}$ Therefore, it can be estimated that the $5.0 \%(\mathrm{w} / \mathrm{w})$ U-CNF-PP composite has the maximum biodegradable properties with low dimensional stability.

\section{Properties of composites Tensile strength}

Unmodified CNF does not show any reinforcement effect because of its incompatible nature with PP. The phase-separated components reduce the tensile strength of the composite. According to Figure 1, for the Si-CNF-PP composites, tensile strength increases with the 


\section{KAHAVITAGE DONA HIMANTHI NIMREKHA KAHAVITA et al.}

loading from 0.5 weight percent to $3.5 \%$. At the $3.5 \%(w / w)$, the Si-CNF-PP sample reaches the highest strength of $27.8 \mathrm{MPa}$. Beyond that, the reinforcing effect of $\mathrm{Si}-\mathrm{CNF}$ diminishes with the increase of Si-CNF loading. The results emphasize that the Si-69 can act as a connecting bridge between the matrix and the reinforcement, improving the compatibility of the two phases up to a CNF loading of $3.5 \%(\mathrm{w} / \mathrm{w})$.

\section{Elongation at break percentage}

The addition of both unmodified and silane modified $\mathrm{CNF}$ to the $\mathrm{PP}$ matrix reduces the elongation at break percentage, with respect to that of Ref-PP, because the addition of a rigid filler can act as a barrier for the dislocation motion (Fig. 6). The elongation at break, at higher levels of U-CNF-PP samples, is reduced because of an increase in the aggregation of the rigid filler. Further, the reduction in the elongation at break of $\mathrm{Si}-\mathrm{CNF}-\mathrm{PP}$ is comparatively higher than that of
U-CNF-PP composite series, owing to the higher compatibility between $\mathrm{Si}-\mathrm{CNF}$ and PP. ${ }^{43}$ The increasing elongation at break from $3.5 \%$ to $4 \%$ might indicate a transformation from a one-phase system to a two-phase system.

\section{Impact strength}

Based on Figure 2, the impact strengths of the Si-CNF-PP composites rapidly increased with the increase of the surface modified CNF percentage within the composite and the maximum value $\left(4.67 \mathrm{~kJ} \mathrm{~m}^{-2}\right.$ ) was achieved by the 5.0 (wt\%) SiCNF-PP composite. The maximum impact strength of the silane-treated CNF reinforced composite is twice higher than that of Ref-PP. The results indicate that an appropriate level of the silane-treated CNF percentage in the PP matrix increases the ability of the material to absorb a greater amount of energy to prevent fracture.

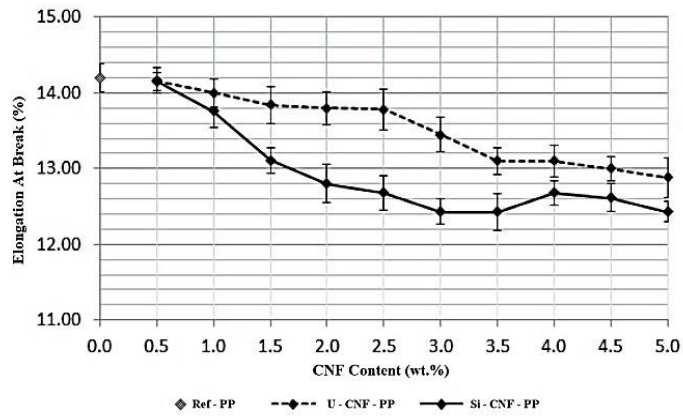

Figure 6: Comparison between the elongation at break percentage of U-CNF-PP and Si-CNF-PP samples with respect to Ref-PP

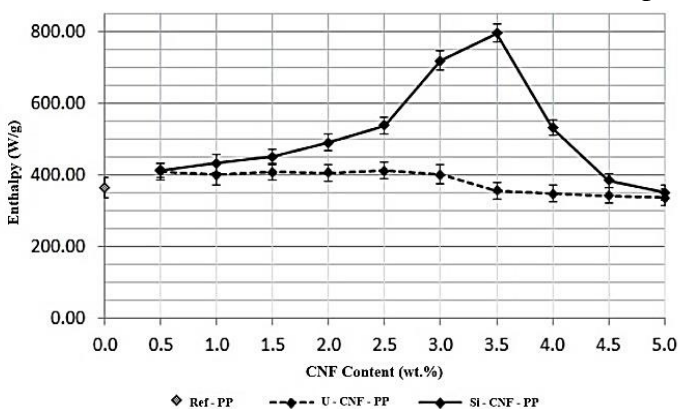

Figure 7: Comparison between the enthalpy of UCNF-PP and Si-CNF-PP samples with respect to Ref$\mathrm{PP}$

\section{Hardness}

The addition of silylated CNF to the PP matrix shows a considerable increase in the hardness up to $3.5 \%(\mathrm{w} / \mathrm{w})$, and then, a minor decline is

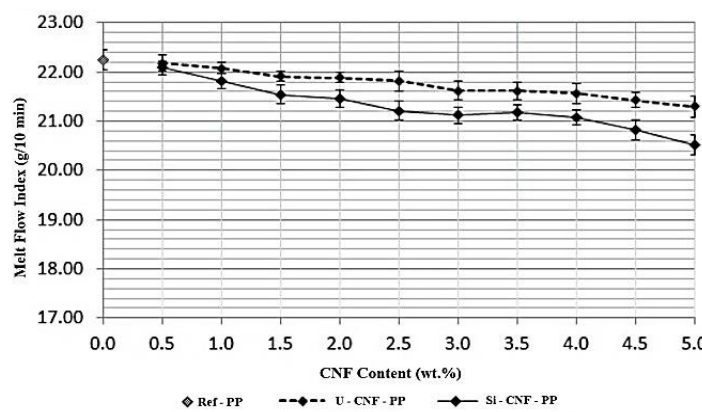

Figure 8: Comparison between the melt flow indices of U-CNF-PP and Si-CNF-PP samples with respect to Ref-PP

observed, along with a decrease of uniformity, with the presence of aggregation (Fig. 3). Therefore, $3.5 \%(\mathrm{w} / \mathrm{w})$ can be considered as the 
optimum amount of silylated $\mathrm{CNF}$ to reinforce composites, as it interacts best with the PP matrix.

\section{Thermal analysis}

The DTA curves of all the samples can be used to state some facts supporting an enhancement in the thermal resistance of composite samples. There is no direct relationship between the melting point and thermal stability; however, a large area beneath the exothermic peaks is equal to an extensive quantity of enthalpy or improvement of heat stability. Figure 7 focuses on the calculated area under the decomposition points of all the DTA curves of the two series. Based on the results, all the Si-CNF-PP composites have improved thermal stability, with respect to Ref-PP. However, the U-CNF-PP series has a reduction of the thermal stability with the improvement of the CNF percentage, because the surface modifier can act as a protective layer and prevents the thermal energy and mass transfer between the reinforcement and the melted matrix. ${ }^{44}$ In addition, there is also a slight reduction in thermal resistance at higher loadings of silylated CNF in the composites, as the interfacial interaction between the matrix and the reinforcement declines. The highest enthalpy of U-CNF-PP series is noted for the $0.5 \%(\mathrm{w} / \mathrm{w})$ loading of $\mathrm{CNF}$, which is significantly lower than the highest enthalpy produced by the $3.5 \%(\mathrm{w} / \mathrm{w})$ Si-CNF-PP composite.

\section{Melt flow index (MFI)}

MFI measures the flow properties of polymeric materials at processing temperature under a standard load. The MFI is indirectly proportional to the viscosity and molecular weight of the material. ${ }^{45}$ High MFI values imply low viscosity and that the energy needed to process the material is low. Economically, it is good; however, the mechanical properties of the final product may reduce because of the reduction of molecular weight. Furthermore, materials with very low MFI values are worthless, because of the requirement of a high amount of energy for the processing. Therefore, it is very important to select a material with an optimum MFI value, which should be high enough to ease the flow and low enough to achieve suitable mechanical properties.

According to Figure 8, an increase in both unmodified and silane modified CNF percentage in PP decreases the MFI values. This test was conducted at $230{ }^{\circ} \mathrm{C}$. At that temperature, the matrix and the reinforcement are in molten and solid states, respectively, as the melting point of $\mathrm{PP}$ is approximately $165{ }^{\circ} \mathrm{C}$ and the decomposition point of $\mathrm{CNF}$ is in-between 300$360{ }^{\circ} \mathrm{C}$. Therefore, $\mathrm{CNF}$ has more heat stable bonds than the PP molecules, and surface modified CNF has even higher thermal stability due to the silane cover around the particles. As a result, the MFI values of the Si-CNF-PP composites exhibit a minor reduction, which is insignificant because all the MFI values of the composites are higher than $20 \mathrm{~g} / 10 \mathrm{~min}$. Therefore, the effect of the reinforcement of PP with both modified and unmodified forms of $\mathrm{CNF}$, up to $5 \%(\mathrm{w} / \mathrm{w})$ loading, on the processability of the material is negligible.

\section{CONCLUSION}

This research aimed to study the performance of the silane (Si-69) surface modifier on CNF reinforcements in PP composites. Generally, the aim of introducing a filler is to achieve a significant enhancement in the mechanical properties of composites. For this purpose, active fillers are of practical interest as they lead to a substantial alteration of the thermal and mechanical properties, as opposed to adding just hard randomly dispersed particles. Compared to unmodified CNF, the surface modified Si-CNFPP composites have substantially increased mechanical properties. The tensile strength of the Si-CNF-PP composites has a rapid rise up to $3.5 \%(\mathrm{w} / \mathrm{w})$ loading. At that loading, the tensile strength increase is over 16\% (against neat PP). Impact strength and hardness also show a significant improvement in the Si-CNF-pp composites. However, because of higher stiffness, elongation at break has reduced considerably. Water uptake has increased, though not to the same extent as in unmodified fiber composites. Overall, these property enhancements suggest that Si-69 based surface modification is very promising to develop good reinforcing agents for PP.

\section{REFERENCES}

T. Hanemann and D. V. Szabó, Materials, 3, 3468 (2010), https://doi.org/10.3390/ma3063468

2 R. H. Marchessault and P. R. Sundararajan, in "The Polysaccharides", edited by G. O. Aspinall, Academic Press, pp. 11-95, 1983, https://doi.org/10.1016/B9780-12-065602-8.50007-8 
3 D. Klemm, D. Schumann, U. Udhardt and S. Marsch, Progress Polym. Sci., 26, 1561 (2001), https://doi.org/10.1016/S0079-6700(01)00021-1

4 A. Ratnakumar, W. S. M. Rathnayake, L. Karunanayake, A. M. P. B. Samarasekara and D. A. S. Amarasinghe, Trop. Agric. Res., 31, 106 (2020), http://doi.org/10.4038/tar.v31i3.8401

A. M. P. B. Samarasekara, M. P. A Nanayakkara, W. G. A. Pabasara, D. A. S. Amarasinghe and L. Karunanayake, in Procs. MERCon Conference, Moratuwa, May 30, 2018, pp. 185-190, https://ieeexplore.ieee.org/document/8421949

6 A. M. P. B. Samarasekara, K. D. H. N. Kahavita, D. A. S. Amarasinghe and L. Karunanayake, in Procs. MERCon Conference, Moratuwa, May 30, 2018, pp. 449-454,

https://ieeexplore.ieee.org/document/8421934

I. M. Saxena and R. M. Brown Jr., Ann. Bot., 96, 9 (2005), https://doi.org/10.1093/aob/mci155

8 W. S. M. Rathnayake, L. Karunanayake, A. M. P. B. Samarasekara and D. A. S. Amarasinghe, Cellulose, 27, 4355 (2020), https://doi.org/10.1007/s10570-02003053-5

9 S. R. Senevirathna, S. Amarasinghe, V. Karunaratne, M. Koneswaran and L. Karunanayake, $J$. Appl. Polym. Sci., $134 \quad$ (2017), https://doi.org/10.1002/app.44475

10 S. H. Osong, S Norgren and P. Engstrand, Cellulose, 23, $\quad 93$ (2016), https://doi.org/10.1007/s10570-015-0798-5

11 S. S. Hindi, Nanosci. Nanotechnol., 4, 73 (2017), http://pubs.sciepub.com/nnr/4/3/1

12 C. Zweben, JOM, 50, 47 (1998), https://doi.org/10.1007/s11837-998-0128-6

13 V. K. Thakur, M. K. Thakur and R. K. Gupta, Int. J. Polym. Anal. Ch., 19, $256 \quad$ (2014), https://doi.org/10.1080/1023666X.2014.880016

14 M. Jonoobi, J. Harun, A. P. Mathew and K. Oksman, Compos. Sci. Technol., 70, 1742 (2010), https://doi.org/10.1016/j.compscitech.2010.07.005

15 T. Wang and L. T. Drzal, ACS Appl. Mater. Interfaces, $\quad \mathbf{4}, \quad 5079 \quad$ (2012), https://doi.org/10.1021/am301438g

16 M. Hietala, A. P. Mathew and K. Oksman, Eur. Polym. J., 49, $950 \quad$ (2013), https://doi.org/10.1016/j.eurpolymj.2012.10.016

17 A. Kaushik, M. Singh and G. Verma, Carbohyd. Polym., $\quad 82, \quad 337 \quad$ (2010) https://doi.org/10.1016/j.carbpol.2010.04.063

18 A. Kiziltas, B. Nazari, E. E. Kiziltas, D. J. Gardner, Y. Han and T. S. Rushing, J. Appl. Polym. Sci., 133 (2016), https://doi.org/10.1002/app.42933

19 S. H. Lee, Y. Teramoto and T. Endo, Appl. Sci. Manuf., $\quad 42, \quad 151 \quad$ (2011), https://doi.org/10.1016/j.compositesa.2010.10.014

20 S. Fujisawa, T. Ikeuchi, M. Takeuchi, T. Saito and A. Isogai, Biomacromolecules, 13, 2188 (2012), https://doi.org/10.1021/bm300609c
21 H. A. Maddah, Am. J. Polym. Sci., 6, 1 (2016), http://journal.sapub.org/ajps

22 R. Crawford and J. L. Throne, in "Rotational Molding Technology", William Andrew, 2002, pp. 19 65, https://www.elsevier.com/books/rotationalmolding-technology/crawford/978-1-884207-85-3

23 K. Yoshino, X. H. Yin, K. Tada, T. Kawai, M. Hamaguchi et al., IEEE Trans. Dielectr. Electr. Ins., 3, 331

(1996), https://ieeexplore.ieee.org/abstract/document/506204

24 J. George, M. S. Sreekala and S. Thomas, Polym. Eng. Sci., 41, $1471 \quad$ (2001), https://doi.org/10.1002/pen.10846

25 J. K. Kim and K. Pal, "Recent Advances in the Processing of Wood-Plastic Composites", SpringerVerlag, Berlin Heidelberg, 2011, pp. 23-57, https://www.springer.com/gp/book/9783642148767

26 L. Wei and A. G. McDonald, Materials, 9, 303 (2016), https://doi.org/10.3390/ma9040303

27 L. D. Rajapaksha, H. A. D Saumyadi, A. M. P. B., Samarasekara, D. A. S. Amarasinghe and L. Karunanayake, in Procs. MERCon Conference, Moratuwa, May 29, 2017, pp. 182-186, https://ieeexplore.ieee.org/abstract/document/7980478 28 M. Jonoobi, J. Harun, A. P. Mathew and K. Oksman, Compos. Sci. Technol., 70, 1742 (2010), https://doi.org/10.1016/j.compscitech.2010.07.005

${ }_{29}$ G. E. Myers, I. S. Chahyadi, C. A. Coberly and D. S. Ermer, Int. J. Polym. Mater., 15, 21 (1991), https://doi.org/10.1080/00914039108031519

30 S. Takase and N. Shiraishi, J. Appl. Polym. Sci., 37, 645

(1989), https://doi.org/10.1002/app.1989.070370305

31 P. H. Nam, P. Maiti, M. Okamoto, T. Kotaka, T. Nakayama et al., Polym. Eng. Sci., 42, 1907 (2002), https://doi.org/10.1002/pen.11083

32 D. Bracho, V. N. Dougnac, H. Palza and R. Quijada, J. Nanomater., 2012, ID 263915 (2012), https://doi.org/10.1155/2012/263915

${ }_{33}$ S. Li, M. M. Lin, M. S. Toprak, D. K. Kim and M. Muhammed, Nano Reviews, 1, 5214 (2010), https://doi.org/10.3402/nano.v1i0.5214

34 Y. Xie, C. A. Hill, Z. Xiao, H. Militz and C. Mai, Composite Part A: Appl. Sci. Manuf., 41, 806 (2010), https://doi.org/10.1016/j.compositesa.2010.03.005

35 M. Abdelmouleh, S. Boufi and M. N. Belgacem, Compos. Sci. Technol., 67, 1627 (2007), https://doi.org/10.1016/j.compscitech.2006.07.003

36 A. M. P. B Samarasekara, S. P. D. A Kumara, A. J. S. Madhusanka, D. A. S Amarasinghe, L. Karunanayake, in Procs. MERCon Conference, Moratuwa, May 30, 2018, pp. 465-470, https://ieeexplore.ieee.org/abstract/document/8421906 37 W. D. Callister and D. G. Rethwisch, "Materials Science and Engineering: An Introduction", John Wiley \& Sons, 2007, pp. 665-715, https://oheg.org/hipo.pdf

${ }_{38}$ R. Karthikeyan, J. Tjong, S. K. Nayak and M. M. Sain, BioResources, 12, $211 \quad$ (2017), 
Composites

https://ojs.cnr.ncsu.edu/index.php/BioRes/article/view/ BioRes_12_1_211_Karthikeyan_Cross_Linking_Densi ty_Sisal_Fiber/4936

39 I. Milosavljevic, V. Oja and E. M. Suuberg, Ind. Eng. Chem. Res., 35, 653 (1996), https://doi.org/10.1021/ie9504381

40 E. Kantarelis, PhD Dissertation, KTH Royal Institute of Technology, 2014

41 J. H. Borchardt and F. Daniels, J. Am. Chem. Soc., 79, 41 (1957), https://doi.org/10.1021/ja01558a009

42 N. F. Aris, R. A. Majid, W. H. W. Hassan, A.

Rahman, M. Faizal et al., "Applied Mechanics and
Materials", Trans Tech Publications, 2014, vol. 554, pp. $123-127$ https://doi.org/10.4028/www.scientific.net/AMM.554. 123

43 H. Salmah, M. Marliza and P. L. Teh, Int. J. Eng. Technol., 13, 94 (2013)

44 Z. X. Zhang, J. Zhang, B. X. Lu, Z. X. Xin, C. K. Kang et al., Compos. Part B: Eng., 43, 150 (2012), https://doi.org/10.1016/j.compositesb.2011.06.020

45 W. Minoshima, J. L. White and J. E. Spruiell, Polym. Eng. Sci., 20, 1166 (1980), https://doi.org/10.1002/pen.760201710 